\title{
El estatuto del maestro
}
Revista Colombiana
Investigaciones de Educación, N. 67.
Segundo semestre de 2014,
Bogotá, Colombia.

\section{//The Statute of the Teacher \\ //O estatuto do mestre}

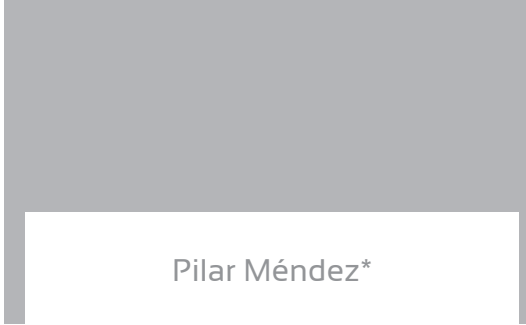

Recibido: 06/09/2014 Evaluado: 11/09/2014

\begin{abstract}
Profesora e investigadora de la Universidad Distrital Francisco José de Caldas. Miembro del grupo de Investigación Intertexto. Candidata a Doctora en Educación de la Universidad Santo Tomás de Aquino. pilarmendezr@hotmail.com, pmendez@udistrital.edu.co
\end{abstract}

\section{Resumen}

En este artículo se discute la intersección de algunos elementos para pensar el estatuto del maestro hoy, a propósito de la tan anhelada búsqueda de la excelencia docente. Discursos sobre la crisis y el desprestigio de la profesión, la calidad docente, la resistencia y el malestar docente aparecen aquí investigados desde un punto de vista temático más que cronológico, que sintetiza ciertos aspectos abordados en la investigación titulada Constitución de sujeto maestro en las prácticas de resistencia en Colombia 1930-2013². El artículo permite advertir la tensión existente entre varios elementos: el estatuto como documento jurídico, los discursos del deber ser del maestro desde la reforma, la identidad de la profesión con un campo del saber que, a su vez, circulan con otros discursos, unos que advierten la crisis de la profesión, mientras otros le apuestan a la excelencia docente como parte central de la reforma.

\section{Abstract}

This article discusses the intersection of some elements to think about the statute of the teacher today, concerning the longed-for search for the excellence in the teaching profession. Discourses on the crisis and the discredit of the profession, teaching quality, resistance and teachers' discomfort appear here investigated from a thematic rather than chronological point of view, that synthesizes certain aspects addressed in the research entitled Constitution of Subject Teacher in the Practices of Resistance in Colombia 1930-2013. The article allows you to notice the tension between a series of elements: the statute as a legal document, the discourses of the teacher's ought self starting from the reform, the identity of the profession with a field of knowledge, which in turn roam with other discourses, some of which point out the crisis of the profession, while others rely on the teachers' excellence as a central part of the reform.

1 Tesis doctoral adscrita a la línea Educación, Derechos Humanos, Política y Ciudadanía del Doctorado en Educación de la Universidad Santo Tomás de Aquino-vuad (Bogotá) dirigida por el doctor Alberto Martínez Boom.

\section{Palabras clave}

Estatuto, profesión, maestro, crisis, excelencia, resistencia.

\section{Keywords}

Statute, profession, teacher, crisis, excellence, resistance.

\section{Palavras chave}

Estatuto, profissão, mestre, crise, excelência, resistência. 


\section{Resumo}

Neste artigo discute-se a intersecção de alguns elementos para pensar o estatuto do mestre hoje, a proposito da tão anelada pesquisa da excelência docente. Discursos sobre a crise e o desprestigio da profissão, a qualidade docente, a resistência e o inconformidade docente aparecem aqui pesquisados desde um panorama temático mais que cronológico, que sintetiza alguns aspectos abordados na pesquisa titulada Constituição de sujeito educador nas práticas da resistência em Colômbia 1930-2013. O artigo permite advertir a tensão existente entre vários elementos: o estatuto como documento jurídico, os discursos do dever ser do mestre desde a reforma, a identidade da profissão com um campo do saber que, a sua vez, circulam com outros discursos, uns que advertem a crise da profissão, entre tanto outros apostam-lhe à excelência docente como parte central da reforma.

Preguntarse por el estatuto del maestro hoy puede conducir a algunos a incurrir en el error de citar de manera precipitada las definiciones de ley que han sido promulgadas en procura de la profesionalización de la docencia, en las que el magisterio sindicalizado advierte la contradicción y la división del gremio, o acudir a las demandas espacio-temporales imbricadas en el deber ser que han instrumentalizado al maestro como producto y efecto de la reforma educativa, de las que generalmente el maestro sale mal librado o no da la talla, o caer en los discursos que reclaman la recuperación de las elaboraciones del Movimiento Pedagógico, a los que muy pocos hoy dan crédito -aunque se sientan interpelados- para reconocer al maestro como portador de un saber: la pedagogía y su autoridad como trabajador de la cultura. En este intrincado laberinto, intentar definir quién es el maestro hoy, y de qué estatuto goza, implica develar múltiples escenarios y distintas fuerzas que se superponen, coexisten y se solapan en la configuración de su situación actual.

Parto de un problema en los términos en los que la opinión pública reitera el lugar común para indicar que "ser maestro oficial es una profesión que está en crisis" (El Tiempo, 26 de abril de 2012); que destaca cuestiones que son problemáticas de vieja data $y$, que han venido adquiriendo matices diferentes de acuerdo con la época. Aludo aquí a los bajos salarios, el bajo desempeño académico, la insuficiente preparación, la profesionalización y la poca valoración social de la profesión, entre otras dificultades laborales. Pareciera que esta época como ninguna otra ha minado la imagen del maestro. Los discursos que reseñan la crisis de la profesión docente en Colombia han proliferado. Al maestro se le responsabiliza del éxito o fracaso 
escolar, se le señala por sus pobres resultados en las pruebas de competencia, se le subvalora frente a otros profesionales por su nivel profesional e ingresos salariales y se le critica por su falta de preparación e incapacidad de asumir su función docente y los desafíos actuales. De hecho, han sido tantas las voces que lo descalifican y le dicen qué debe ser y cómo debe hacer su trabajo, que entre maestros y docentes ya no se divisan rasgos distintivos de autoridad, respeto y prestigio. ¿Qué dicen los maestros de esta problemática? ¿Cuál es el campo de tensiones en los que se debate hoy la condición docente?

La imagen del maestro virtuoso que otrora era admirado y reconocido por ser poseedor de un saber y dedicarse a una obra excelsa, la enseñanza, es hoy casi imperceptible. Algunos investigadores no dudan en señalar su dilución (Martínez Boom, 2010), su malestar (Esteve, 1987), su frustración, su cosificación (Díaz, 1983), su lugar en la encrucijada (Tiramonti, 2005), su insatisfacción (Braslavsky, 1994), en fin, afirmaciones que ponen de manifiesto que algo anda mal en la educación y en ella con el reconocimiento del estatuto del maestro.

En este contexto, llamo la atención primero sobre una apuesta para intervenir esta situación: El afán por elevar la calidad y el estatus del maestro $^{2}$, que puede ser corroborado con

2 La pérdida de prestigio y estatus social de maestro se extiende a nivel mundial. Un estudio denominado The Global Teacher Status Index dos ejemplos concretos, uno proveniente del discurso oficial (Ministerio de Educación Nacional-Foro Maestro Siempre) y otro del conocimiento experto (Fundación Compartir, Documento Tras la excelencia) que ubican al maestro como eje central de una política de mejoramiento de la educación en general, en los que no obstante la insistente recurrencia al enunciado maestro no se le desvincula del discurso del deber ser, impuesto de funciones, competencias y roles diversos que sirven más a la figura de la función docente. Se percibe en estos discursos el afán por cooptar al maestro, alinearlo con las políticas de turno, convencerlo incluso con sus propias consignas de dignificación de la profesión, de que el camino oficial es el camino de su redención.

Segundo, Ilamo la atención sobre una modificación crucial. De la docencia entendida como una práctica de saber, ligada a condiciones de posibilidad de un maestro como sujeto activo a la docencia como función docente opera toda una instrumentalización que constriñe su condición. Aludo aquí a un tipo de maestro, no muy creído, no muy

(2013), de Varkeys Gems Foundation, se ocupó de medir el nivel de respeto por los maestros en diferentes países, encontrando que en los países muestra los maestros ya no conservan el elevado estatus del que solían disfrutar. El estudio parte de un supuesto clave "si los profesores no son respetados en la sociedad, los niños no los escucharán en clases, los padres no reforzarán los mensajes que vienen de la escuela y los recién graduados más talentosos continuarán despreciando la docencia como profesión" (p. 4) (texto traducido del inglés).

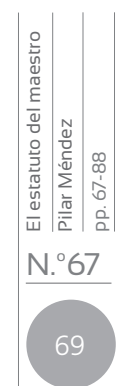


visible, pero aún presente aunque desplazado. El maestro en resistencia. Un maestro que no se pliega a las demandas, que no se identifica con los discursos del deber ser ni con retratos de maestros pasados, que entiende que cada época cambia el piso de su saber y que lucha por abrir un espacio suyo de existencia en la que su estatuto como profesional no se mancille y se cuestione. Un maestro que no se define por una función sino que se constituye día a día en su práctica pedagógica.

En dicha perspectiva, una mirada a las prácticas de resistencia de los maestros en relación con sus deseos de estatus profesional, reconocimiento y valoración puede abonar a la comprensión de su situación actual para contrastar cómo se percibe la docencia desde afuera (el gobierno, los medios de comunicación y la sociedad en general, el conocimiento experto) y desde adentro (los maestros, sus organizaciones, el conocimiento de investigadores de la educación) con el fin de revelar las tensiones en estas relaciones. Se necesita entender cómo las fuerzas políticas, económicas, culturales y sociales afectan al maestro para dar cuenta de su posición social, el respeto por la docencia, su promoción como opción laboral, la consideración de su remuneración y condiciones de trabajo, los niveles de respeto y confianza en la labor docente y las luchas de los maestros por mejorar su situación (Hargreaves, Cunningham et al., 2006).

\section{Ser maestro oficial, profesión en crisis}

Año 2012: El titular del periódico El Tiempo "Ser maestro oficial, una profesión que está en crisis" desató un sinnúmero de reacciones y opiniones alrededor de la imagen del maestro. Los bajos resultados obtenidos por los maestros en formación en las pruebas Saber Pro (2011) fueron el detonante de un análisis que exploró, por un lado, los problemas en materia de selección, vinculación y estímulos para atraer y retener a los mejores bachilleres a la carrera y, por otro lado, la falta de formación, los pobres niveles de desempeño y el perfil general de los maestros en ejercicio, así como críticas a la falta de renovación curricular en las facultades, todo ello aunado a una mínima progresión salarial y un pobre reconocimiento social. Como resultado de este análisis se infiere que se debe formular una política de formación docente que atraiga a los mejores bachilleres, resolver los problemas del magisterio en ejercicio con mejores y mayores estímulos, no solo monetarios, y elevar el prestigio social 
de la profesión para que sea más atractiva.

Frente a la noticia, los maestros reaccionaron. Algunos la asumieron como una crítica que rayaba en la ridiculización a los maestros y se sumaba a la falta de valoración social y reconocimiento del mismo; muchos manifestaron sentimientos de tristeza por la invisibilización en la prensa de experiencias significativas de su labor y por la falta de un sistema de incentivos para mejorar su situación (Martínez, M., 2012). Mientras que otros, haciendo uso de la herramienta Comentarios, al pie de la noticia, no dudaron en afirmar que ser docente en Colombia -en comparación con otros países- es un desprestigio, lamentaron los bajos sueldos, la falta de estímulos, las escasas oportunidades de preparación y de ascenso en el escalafón y el continuo asedio de la evaluación de su desempeño y competencias. Un detallado análisis de las voces del público lector en general en contrapunteo con otros participantes, algunos de ellos maestros, puede ser revelador de los señalamientos al maestro y de sus respuestas:

Un lector con una imagen del maestro sindicalista de perezoso y burdo afirma:

Barreral: Para 2011 de acuerdo al Decreto 1055/2011 un recien (sic) graduado grado 2 a tenía un sueldo de 1'263.000, un profesor con maestría grado $3 \mathrm{~d}$ sueldo de
4'771.000, fuera de las arandelas, que tal? Los profesores en realidad no se preparan como debe ser, pero si estan (sic) listos a marchas, paros $y$ protestas por su sueldo. Tienen la oportunidad de hacer posgrados a costa del estado para que mejoren su nivel, pero son peresozos (sic), trabajan medio tiempo (por eso se les paga medio tiempo), son ignorantes, burdos y sindicalistas. La mayoría parecen camioneros $y$ guisas, deben es ponerse a trabajar en vez de estar montando huelgas y protestas. Cuantos profesores están en el escalafón mas (sic) alto? hay que pagarles servicio de salud especial y aún así se quejan. vaya!! Miren un profesional recien (sic) graduado a ver cuanto (sic) le pagan y cuanto tiene que trabajar (jueves 26 de abril de 2012 08:40 a. m.).

Inmediatamente otro lector, con expresiones de solidaridad y comprensión de la situación de los maestros, le recrimina a Barrerai por su desconocimiento de la situación del docente:

Misterwilliam: Barrerai, se nota su resentimiento por la vida y su 
desconocimiento de la vida de un docente. Yo soy un profesional de ingeniería, con varios años de experiencia y sé cómo es este régimen, también provengo de una familia de docentes y sé por justa causa que eso que usted menciona no es más que una sarta de mentiras y mala percepción -por culpa de medios o ideales capitalistas-; pero los docentes se esfuerzan más de lo que usted piensa, su jornada laboral no termina saliendo de un salón de clases y los pocos beneficios que el gobierno les da -que deberían más bien ampliarlos a otros sectores- en vez de mejorarlos se presume en eliminarlos. Los docentes no gozan de formación gratuita, ni súper salarios como usted cree, porque estoy seguro que no le consta... entonces en vez de desinformar más a la gente, primero investigue. Soy un empleado en una empresa privada y apoyo la protesta de los docentes! (jueves 26 de abril de 2012 09:46 a.m.).

Frente a los comentarios desfavorables sobre su imagen, algunos maestros participaron defensivamente; explicando las características y condiciones de su trabajo:

Anyrose: La ignorancia es atrevida dice mi madre y veo que es real, ya que nosotros no nos inventamos las vacaciones o el tiempo de descanso y cuando reposamos en semana santa es porque hemos tenido que trabajar 3 sábados reponiendo los tres días lunes, martes y miércoles santos, todo el tiempo llevamos trabajo a casa y cuando los estudiantes salen de vacaciones nosotros debemos trabajar en proyectos y asistir a capacitaciones para poder ofrecer una educación de calidad a nuestros educandos y si piensas así es porque tal vez sufriste mucho en tu época de estudiante cuando algún docente te exigió rendimiento en su asignatura y no diste la talla por eso nos críticas. ¡Sana esa herida y se objetiva! (domingo 29 de abril de 2012 05:34 p.m.).

Los anteriores fragmentos ${ }^{3}$ permiten advertir una tensión entre valoraciones positivas y negativas de la profesión y los maestros, donde convergen sentimientos de solidaridad y justificación por un lado, y de recriminación e invalidación, por el otro. En todo

3 Muestra de 150 comentarios al pie de la noticia de la crisis de la profesión, entre 23 participantes, publicada en El Tiempo (2012, 25 de abril). 
caso, fue mayor la proporción de comentarios que señalan como causa de la mala calidad de la educación al docente. Al docente viejo, en edad pensional, por su falta de innovación; al docente joven, recién vinculado, por su falta de experiencia; al docente sindicalizado por su codicia, al docente quejumbroso porque no valora sus privilegios (v. g. "cómoda jornada laboral, vacaciones, sueldos"). En la tabla 1 se transcriben los términos utilizados para calificar a los maestros y a la docencia.

Tabla 1. Valoraciones sociales del maestro y la docencia.

\begin{tabular}{|c|c|c|}
\hline \multirow{20}{*}{$\begin{array}{l}\text { En el plano } \\
\text { negativo }\end{array}$} & Maestro & Docencia \\
\hline & Tiene un bajo nivel de formación. & Es la cenicienta de las profesiones. \\
\hline & Está desactualizado. & Es una profesión ingrata. \\
\hline & Está desfasado. & Goza de poco reconocimiento. \\
\hline & Es tradicionalista. & Está muy mal remunerada. \\
\hline & Es vago. & $\begin{array}{l}\text { Se desarrolla en difíciles ambientes de } \\
\text { trabajo. }\end{array}$ \\
\hline & Es amargado. & Tiene un escalafón tortuoso. \\
\hline & El joven carece de experiencia. & Es sostenida por asistencialismo. \\
\hline & El viejo está quemado. & Tiene pocos y bajos estímulos. \\
\hline & Vive sometido al gobierno. & $\begin{array}{l}\text { Recargo de responsabilidades propias } \\
\text { de la familia. }\end{array}$ \\
\hline & Vive sometido al padre de familia. & Padece excesivo control estatal. \\
\hline & Vive discriminado. & \multirow{2}{*}{ Está desprestigiada. } \\
\hline & Es constantemente ofendido. & \\
\hline & Es mediocre. & $\begin{array}{l}\text { Es la alternativa de rebusque para otros } \\
\text { profesionales. }\end{array}$ \\
\hline & Es comunista. & \multirow{6}{*}{$\begin{array}{l}\text { Es el remedio al desempleo de otros } \\
\text { profesionales fracasados y frustrados. }\end{array}$} \\
\hline & Está condenado. & \\
\hline & Es codicioso. & \\
\hline & Es sindicalista. & \\
\hline & Es mamerto. & \\
\hline & Está sometido al sistema. & \\
\hline \multirow{4}{*}{$\begin{array}{l}\text { En el plano } \\
\text { positivo }\end{array}$} & Es un incomprendido. & Es una profesión digna de admirar. \\
\hline & No es valorado en su justa medida. & $\begin{array}{l}\text { No es una profesión para todo el } \\
\text { mundo. }\end{array}$ \\
\hline & Aporta mucho a la sociedad. & \multirow{2}{*}{$\begin{array}{l}\text { Requiere altas dosis de vocación y } \\
\text { entrega. }\end{array}$} \\
\hline & Es un sacrificado. & \\
\hline \multirow{7}{*}{$\begin{array}{l}\text { Desde el } \\
\text { deber ser }\end{array}$} & $\begin{array}{l}\text { Debería tener un estatus muy superior } \\
\text { (salarial y socialmente). }\end{array}$ & \multirow{2}{*}{ Debe ser un apostolado. } \\
\hline & Debería ser más comprometido. & \\
\hline & Debería ser más valorado. & \multirow{2}{*}{$\begin{array}{l}\text { Debe ser más entendida su compleja } \\
\text { tarea. }\end{array}$} \\
\hline & Debería tener más autonomía. & \\
\hline & Debería prepararse mejor. & \multirow{3}{*}{$\begin{array}{l}\text { Debe ser apoyada por la familia, el } \\
\text { Estado y la sociedad. }\end{array}$} \\
\hline & Debería manejar la tecnología. & \\
\hline & Debería ser bilingüe. & \\
\hline
\end{tabular}


Sentimientos de indignación, tristeza y justificación de los maestros participantes hacen notar su rechazo a las valoraciones negativas, a su juicio, por desconocimiento de su situación y por efecto de la mala prensa. Igualmente pueden verificarse sentimientos de inconformidad con las condiciones de trabajo de la docencia que tildan de injustas, desestimulantes e insolidarias.

Angemariru: Condenar a un maestro porque quiere un mejor salario (porque hay muchos maestros endeudados por las maestrías y doctorados que en Colombia son demasiado costosos comparados con la remuneración salarial), porque quiere salud digna (los invito a las salas de urgencias de las clínicas que nos atienden que dista mucho de ser igual a la salud prepagada), porque queremos que nuestra profesión no sea la cenicienta de todas las profesiones. Me entristece todos los comentarios de quienes somos formados en las facultades de educación y de la formación pública, porque nunca vemos a los medios en los colegios públicos destacando la labor positiva que hacemos, porque nunca vemos a los medios en un foro educativo (son espacios dedicados a mostrar las experiencias pedagógicas significativas), se hacen todos los años en todos los municipios del país y que enriquecen nuestro quehacer (viernes 27 de abril de 2012 04:51 p.m.).

Cuando Esteve (1995) analiza los sentimientos de tristeza, angustia, depresión y estrés en el profesorado para explicar el "malestar docente", da cuenta del impacto que tienen factores del componente social en el ánimo de los maestros, tales como: el deterioro social de su imagen, las cargas sociales de sus estudiantes, las demandas de su actualización, las múltiples y variadas exigencias que debe cumplir (científicas, técnicas, culturales, pedagógicas, psicológicas y sociales), los encargos de crianza, el manejo de la tecnología, su falta de autonomía, la falta de recursos, las agresiones verbales, físicas y psicológicas en su contra, entre otras (Natale, 1993; Young, 2004). Esto se traduce en una situación altamente compleja que los maestros deben soportar, algunos para sobrellevar la culpa, y otros para encontrar fuentes de motivación y no abandonar la carrera ${ }^{4}$ (Marlow, 1996).

4 Frente a este fenómeno existe cierto nivel de consenso entre autores como Marlow et al. (1996), Keiper y Busselle (1996), Friedman (1995), quienes han analizado cómo sentimientos de estrés, frustración y falta de apoyo (Keiper y Busselle) han contribuido a 


\section{La mala calidad del docente}

Año 2013: "La mala calidad de los docentes es quizás el factor más determinante". Esta afirmación sobresale en el análisis realizado por el periódico El Tiempo (8 de diciembre), luego de conocerse los resultados alcanzados por los estudiantes colombianos en las pruebas PISA. Una vez más se señala como razón de esta problemática al maestro, sus pobres prácticas pedagógicas y consecuentemente a la pobre calidad de la formación docente. El artículo determina que se debe resolver el problema desde la raíz, interviniendo las facultades de Educación para que mejoren su desempeño y el currículo de formación docente. Mientras la esperanza pareciera depositarse en los futuros maestros, lo que pasa con los maestros en ejercicio se retrata desde una aparente sin salida:

En Colombia las carreras relacionadas con la docencia son elegidas por quienes sacan los peores puntajes en las Saber 11, quienes, a su vez, reflejan el mismo desempeño al finalizar la universidad, en las Saber Pro; esto es preocupante porque son

que los profesores consideren la posibilidad de abandonar la profesión (Marlow, 1996). Friedman alude a la falta de respeto como un aspecto difícil de asumir por el profesorado, mientras Natale (1993) y Young (2004) se refieren al desgaste al que es sometido el maestro. ellos quienes tendrán la responsabilidad de formar a los nuevos alumnos (Rodríguez, C. investigadora de la Fundación Compartir. En periódico El Tiempo, 2013).

La valoración de la calidad de la educación con énfasis en los resultados de las pruebas internacionales ha intensificado los discursos que reclaman "maestros de calidad" que puedan mejorar estos resultados y ubicar a Colombia en una mejor posición en la clasificación. En este enfoque de medición, validación y competitividad, el maestro es una variable muy importante para impulsar una política de calidad educativa que asegure el sistema. Recomendaciones del discurso experto, como las realizadas por la Fundación Compartir abonan a esta tendencia, sugiriendo una propuesta de reforma sistémica que se centra en el mejoramiento de la calidad docente, a través de iniciativas que van desde la promoción de una mayor valoración social de la profesión docente; el reclutamiento de los mejores bachilleres a la carrera docente; el establecimiento de estándares más altos en los programas de formación docente previa y en servicio (con énfasis en la práctica y la investigación pedagógica); el acompañamiento y la evaluación docente y esquemas más atractivos de remuneración que incluyan salarios e incentivos monetarios y en especie (Fundación Compartir, 2014, p. 6). 
En otras palabras, como parte de una política de mejoramiento de la calidad educativa, se desplaza al niño, y se busca que el maestro se convierta nuevamente en el foco de interés de la política educativa. Llamo la atención sobre este desplazamiento nada novedoso en las reformas educativas colombianas (que han justificado en el pasado el desplazamiento del maestro al niño $y$, ahora del niño al maestro $)^{5}$ que obligan al Ministerio de Educación Nacional (MEN) a reconocer que:

El maestro es el pilar del proceso educativo [...] hemos redescubierto al maestro, nos volvimos a preguntar por él, aunque siempre estuvo allí, él es el centro de la política educativa [...] si no tenemos maestros de calidad, no tendremos estatus de calidad (Campo, 2014. Foro Maestro Siempre).

No obstante, habría que sospechar de esta afirmación. ¿Sí será que se alude al maestro?, o ¿será un enunciado cooptado, utilizado como comodín para emplazar al docente? Aunque estas afirmaciones ponen de manifiesto una apuesta política por la recuperación de la imagen central del "maestro" en el proceso educativo -que busca intervenir al maestro desde su formación hasta su vinculación y ejercicio docente por medio de un esquema donde primen el acompañamiento y la evaluación- en su aparente bondad no deja de advertirse la desconfianza, el extremo control que se pretende de su persona, del cerco de su poco espacio de libertad y autonomía; pues al maestro no se le puede dejar actuar solo, su desempeño debe ser evaluado y su formación debe estar regulada y asegurada por efectivos mecanismos de observación. De aquí se implica un pacto tácito: ¡Docente, comprométete con este enfoque de calidad y a cambio recibe el estatuto de calidad que reclamas!

Los maestros han resentido este enfoque de la calidad centrada en los resultados de exámenes estandarizados, así como los estudios que solo se centran en el maestro como una variable de esta problemática. En relación a las Pruebas PISA como rasero para medir la calidad, 83 maestros y expertos en políticas educativas de todo el mundo critican su metodología y exponen una serie de preocupaciones frente a las consecuencias que puede tener el escalafón hecho por la Organización para la Cooperación y

5 Digo nuevamente porque en el año 2002, a propósito de la definición del Estatuto de profesionalización docente (Decreto 1278 de 2002), el discurso oficial justificaba la medida, aludiendo el desplazamiento del maestro al niño. 
el Desarrollo Económicos-OCDE- (El Espectador, 13 de mayo de 2014). No dudan en señalar que el método de las pruebas PISA es "sesgado", obliga a que los colegios actúen en pos de la competencia y los resultados en algunas áreas, más que "tras propósitos educativos menos medibles, como el desarrollo físico, moral o artístico". Para estos expertos, este énfasis reduce la autonomía de los profesores y genera estrés en las escuelas. Lo que puede leerse como un reclamo de los maestros por recuperar el derecho a dirigir su trabajo, la autonomía y autoridad para decidir los propósitos de la educación que imparte y las características de la formación que reclama. Se trata de resistir un enfoque de evaluación de la calidad que se queda corto frente al esquema valorativo de los maestros, más ligado con la formación y la cultura.

Los estudios que solo tienen en cuenta la variable docente como eje central de una política de mejoramiento de la calidad de la educación en general parecen no asir la complejidad del problema. Los citados para sustentar esta propuesta, mayoritariamente han sido realizados en países con condiciones sociales, políticas, culturales disímiles a las de Colombia y, por tanto, no atienden otras variables que deben sopesarse simultáneamente (currículo, enfoque de calidad, tipo de evaluación, proyecto educativo, nutrición, número de estudiantes por clase, recursos educativos, propósitos de formación, etc. ${ }^{6}$. Sin desconocer la importancia del estudio Tras la excelencia, algunos autores no dudan en señalar que para nuestro caso "no basta tener buenos docentes":

Nadie puede negar que sea imposible elevar la calidad de la educación sin mejorar los criterios de selección y evaluación de los docentes. Sin embargo, la propuesta se queda realmente corta en el análisis de otras variables asociadas a la calidad, particularmente en lo que tiene que ver con los factores propiamente pedagógicos como el currículo, la reflexión pedagógica, la selección de competencias básicas, el liderazgo pedagógico del director o el modelo pedagógico adoptado en la institución (Zubiría, J. 2014).

Ninguna propuesta de reforma puede garantizar el éxito si desestima otros problemas conexos o se desconoce la realidad histórica de la escuela (Martínez Boom, 2014). El diagnóstico frente a lo que sucede

6 Por ejemplo, los estudios de Chetty, Friedman y Rockoff (2011) sobre el impacto a largo plazo de los profesores y su valor agregado a los estudiantes, así como los de Bill \& Melinda Gates Foundation sobre el éxito docente, tomados como referentes para Colombia en el estudio de la Fundación Compartir fueron llevados a cabo en Estados Unidos. 
con la educación y los maestros en general es aún más complejo. La idea de que la docencia es una profesión en crisis y, en ella, la de que el maestro es responsable de la mala calidad de la educación, han tomado tanta fuerza que el anuncio de su crisis se valida como una estrategia que prepara el terreno de una reforma que pueda contenerla ${ }^{7}$. Pero lo que no se reconoce con ello es el fracaso de las últimas reformas que han intervenido al maestro, su labor y el estatuto epistemológico de su profesión. En este ámbito de actuación la relación reforma-dores (desde arriba), objetos y sujetos a reformar (maestros, educación, currículo, facultades) se contraponen en un haz de relaciones de fuerza por intervenir lo que está sucediendo, con la esperanza de generar un cambio, pero con la incertidumbre de no poder garantizar los efectos y resultados de la misma.

\section{La docencia y su poca capacidad de atracción}

Los maestros somos considerados pésimos; una caterva de 'izquierdosos', que hace paros para exigir reivindicaciones como salud, vacaciones y pensión, y que protesta porque le aumentan el número de estudiantes y la carga académica. ¿Estudiar pedagogía? Te vas a morir de hambre, es la reacción automática. ¿Acaso qué colombiano se enorgullece de tener un hijo maestro, como se ufana de tener hijos médicos o abogados? Contrariamente a lo que sucede en países como Finlandia, donde ser maestro tiene gran prestigio social, lo cual se refleja en los resultados de las pruebas PISA, en la excelencia requerida para ingresar a la carrera docente y en buenos salarios, el maestro colombiano es considerado un profesional de segunda. Si estudió pedagogía fue quizás porque no le

7 La crisis en la educación no es una cuestión novedosa. Para finales de la década del 60 Coombs había declarado la crisis mundial de la educación, destacando entre sus elementos el maestro como una variable de la misma. De tan buen recibo fue su análisis que en el país los ministros y la prensa de la época citaban constantemente la crisis para diagnosticar que "la primaria está en crisis, la secundaria está en crisis, la superior ni se diga.. crisis académica y administrativa por el profesorado obsoleto y las directivas aleladas" (La República [1971], octubre 2, p. 4). La reforma que produjo el Decreto 1278 de 2002, enmarcada en elevar la idoneidad y la calidad de los maestros con el reclutamiento de un "nuevo maestro" (MEN, 2008), habilitado para ejercer la función docente, luego de los resultados de las pruebas internacionales, exacerba su fracaso (aunque no se publicite), traslada la responsabilidad de la mala calidad de la educación al maestro y anuncia la crisis como una estrategia para declarar la alerta y preparar el terreno para futuras reformas. 
alcanzó el Icfes para hacer "una carrera seria". Si pide un sueldo decente $y$ tiempo remunerado para leer, investigar, preparar clases, evaluar o, simplemente, recuperarse de sus extenuantes jornadas, le endilgan "falta de mística". Porque esa es otra representación social: maestro se asocia con sacrificio, apostolado, paciencia y pobreza ( $E I$ Tiempo, 2012, columna de opinión, febrero 19).

De acuerdo con Preal (2010), "la escasa valoración que recibe la profesión docente en América Latina es hoy un problema recurrente". Uno de sus estudios mostró que entre los docentes de siete países de la región había "un sentimiento de pérdida de prestigio y deterioro de su imagen frente a la sociedad, lo que se traduciría, entre otras cosas, en el decreciente número de bachilleres talentosos que optan por la docencia" (GTD-Preal, 2010, p. 1). De hecho, la proliferación de discursos desfavorables frente al maestro como el responsable directo del fracaso de la política educativa de calidad, y la crisis de la docencia como opción profesional, ha incidido notablemente en la percepción de los padres de familia que no validan esta carrera como la primera opción de estudios de sus hijos.

"Y tú ¿quieres que tus hijos sean docentes?" Así interpela Ñopo, H.
(14 febrero de 2014) a los lectores de su blog en la página del BID, al mostrarles una radiografía de la situación laboral de los maestros en América Latina, que le sirve de pretexto para explicar que se está fallando en atraer y retener a los mejores maestros, así como en la capacidad de estimular el apoyo de los padres a la docencia como mejor opción profesional para los hijos:

Supongamos que tienes un hijo (sobrino, ahijado o amigo joven) profesional y mañana le ofrecen un empleo diciéndole que "ganará entre 30\% y $70 \%$ menos que otros profesionales con la misma edad y años de educación". Además le dicen que "tres de los seis puestos de trabajo disponibles no tienen teléfono y, es más, dos de ellos no tienen acceso a un baño decente". ¿Le recomendarías tomar el empleo? Bueno, hay más de tres millones de personas que día a día trabajan en esas condiciones en América Latina: los maestros de las escuelas primarias $y$ secundarias.

Como puede deducirse, el origen predestinado de la clase media al oficio de maestro ${ }^{8}$, las críticas por

8 Sirve aquí revisar los datos de un estudio del IDEP de 2009, titulado "Perfiles de los docentes del 
su deficiente preparación, la baja valoración social y remuneración salarial de su trabajo son variables que desestimulan la vinculación de los jóvenes a la carrera, principalmente de aquellos que pueden ser considerados talentosos. Entre estas variables, la de mayor peso tiene que ver con la consideración salarial. Año 2012, bajo el titular "Los peor pagos", la revista económica Portafolio, haciendo un análisis de los salarios de los egresados en Colombia, indicó que:

Y si la minería es lo que da más plata, en el otro extremo están los de siempre: los 'profes' (...) de las 10 carreras universitarias peor pagadas, seis tienen que ver con licenciaturas. La de preescolar encabeza la lista, de la que también hacen parte fisioterapia y música, en cuarto y quinto lugar. Los únicos profesores que clasifican entre las 50 carreras mejores pagadas son los licenciados en educación básica con énfasis en inglés, que ocupan el puesto 48 y reciben, en promedio, un sueldo inicial de 1'464.735 pesos.

Frente a esta realidad, no ha de extrañar que el estudio Tras la excelencia (Fundación Compartir, 2014) proponga un esquema que aumente el salario de los maestros, dependiendo de sus niveles de estudios, desempeño y cargos dentro del sistema para hacerlos más competitivos, ya que el salario actual de los docentes sigue estando muy por debajo del devengado por otros profesionales, como médicos, abogados e ingenieros ${ }^{9}$. Sin embargo, habría que precisar que el estatuto de "profesión" con la carga cultural que antes se tenía, ha decaído ${ }^{10}$. Desde esta perspectiva, la nivelación salarial de la docencia con otras profesiones se asume como un reto crucial para mejorar su estatus. Aunque este es un aspecto bastante optimista de la propuesta de reforma de la Fundación Compartir, aún debe pasar el filtro de la política económica de gasto e inversión y de las consideraciones

sector público de Bogotá" que señala que un 63,3\% de los docentes de Bogotá declaran pertenecer a la clase media, mientras un $24,8 \%$ de los encuestados se identifica con la media baja. Ninguno de los encuestados responde clase alta y un 1,8 responde clase baja.

9 Un estudio del Observatorio Laboral del Ministerio de Educación (2011) permite comparar los salarios de enganche entre distintos profesionales: médicos, $\$ 2.584 .314$; ingenieros, \$2.060.000; abogados, \$2.032.832; docente 2277 cat. 7, \$1.188.666 (2014) Docente 1278 Grado 2, Nivel A $\$ 1.411 .890$ (sueldo 2014).

10 Las profesiones liberales como la medicina y el derecho ya no gozan del prestigio, el reconocimiento social y la remuneración de antes. Niveles de especialización y doctorado también se exigen para mejorar su condición en un contexto altamente competitivo. 
alrededor del tiempo de trabajo de los docentes ${ }^{11}$ que año tras año reciben un aumento salarial por debajo de la inflación.

Ahora bien, otro aspecto a considerar, como lo menciona Nopo (2014), son las precarias condiciones de las escuelas en las que se desempeña el docente.

Problemas de insalubridad ${ }^{12}$, hacinamiento $^{13}$, violencia, matoneo ${ }^{14}$,

11 A través de distintas formas de lucha, huelga, protestas, pliegos de peticiones; el incremento del salario ha sido un elemento que históricamente ha pervivido en las luchas por la reivindicación del maestro. La comparación del salario entre profesiones ha sido un aspecto clave para librar la batalla de la nivelación salarial con profesiones de similares demandas y años de estudio. Para Natale (1993) este factor ha sido fundamental para comprender los grados de insatisfacción de los maestros, su oposición y lucha. Las prácticas de resistencia de los maestros orientadas a elevar el estatus de la docencia de oficio, actividad o función a profesión, examina entre otras cuestiones, que el salario compense las actividades extra-aula (preparación de clase, corrección de exámenes, discusión del PEI) inherentes a las demandas de la profesión, que no se comparece con los discursos que consideran que el maestro solo trabaja medio tiempo.

12 Sirva como ejemplo la noticia del Canal RCN de 20-11-2012 (emisión de las 8:44 p.m.), que indicó que "15 colegios de convenio en Bogotá están en condiciones insalubres". Se aseguraba que "Los baños están sin tapas, los salones de clase están decorados con costales y las ventanas rotas son reparadas con bolsas de basura negras".

13 Una mirada a la página de periodismopúblico. com permite corroborar la situación en una escuela de Soacha, cuyo grado de hacinamiento es tal, que una investigación determinó que a cada estudiante le correspondería un espacio en su momento de descanso del $0.80 \mathrm{~m}^{2}$, es decir un espacio de comodidad menor a los $1.20 \mathrm{~m}^{2}$ recomendados por la norma arquitectónica colombiana para ambientes escolares.

14 Baste con leer la noticia de que "Colombia es uno de los países con mayores cifras de matoneo" de vanguardia.com (del 15 de marzo de 2012) que comparte los resultados de la investigación de Chaux, E. sobre la materia. amenazas $^{15}$, etc., que deben sortear los docentes en su ambiente de trabajo; lo que ha producido que la docencia sea calificada como una profesión peligrosa ${ }^{16} \mathrm{O}$ de alto riesgo.

De acuerdo con algunos expertos e investigadores, la docencia perdió su "capacitad de atracción, es decir, que no son los jóvenes con mejores resultados educativos, los que optan por estudios de maestro o de profesor" (Vaillant, 2010). Particularmente en Colombia, "Ios jóvenes más talentosos optan por carreras que exigen puntajes más altos, son de mayor prestigio y pueden ser más lucrativas" (El Tiempo, 2012, panel de expertos). Lo que conduce a afirmaciones lapidarias: "Los que se están formando para maestros no son los de mejores desempeños" (Ñopo, 2014).

De estos discursos se infiere un pobre o nulo reconocimiento a la posibilidad de la elección por convicción, vocación o disposición aptitudinal de la docencia independientemente de los resultados en las Pruebas Saber 11. Con el desprestigio social y la baja remuneración de la docencia, pareciera inconcebible que los jóvenes aún optaran libremente por ella o que algunos profesionales la abrazaran

15 En el siguiente link: http://www.eltiempo.com/ noticias/amenazas-a-profesores se puede leer un inventario del periódico El Tiempo sobre las amenazas a los profesores provenientes de grupos armados, padres de familia, anónimos, etc.

16 Una columna de Ramón Ábalo en el blog La Quinta Pata da cuenta de este calificativo. Mientras en la página de Internacional de la Educación para América Latina no se duda en afirmar que la docencia es una profesión de alto riesgo. 
más por convicción que por auxilio o remedio de su situación económica.

\section{El gremio herido}

Se advierte en los actuales discursos de los maestros que reclaman un único estatuto de profesionalización de la docencia, la sensación de una pérdida. ¿Pérdida de una impronta de lucha? ¿De unas condiciones de posibilidad de ser maestro hoy? Hay un sentimiento de nostalgia por la fuerza de las luchas de ayer que obliga a reclamar nuevas estrategias:

¿Cómo leer este absurdo y ambiguo caso de contar con dos marcos legislativos para regular el ejercicio de una profesión? ¿Qué hacer? ¿Cuáles son las acciones inmediatas? Considero que es necesario ampliar la resistencia, reenfocar el trabajo y reforzar la movilización con nuevas y contundentes estrategias [...] se está desvertebrando el colectivo magisterial, se están ampliando las brechas entre los maestros del viejo y el nuevo estatuto y se está vulnerando el derecho a la igualdad. Y, lo más lamentable, es que se percibe un agotamiento de los actores, la desesperanza se ha instalado en los maestros y este es un síntoma muy grave (Fecode, 2012).

El anterior discurso de Fecode es tanto súplica como interpelación al gremio dividido, que poco le reconoce ${ }^{17}$, por encontrar nuevas estrategias, capaces de recuperar el sentido que dio el Movimiento Pedagógico colombiano ${ }^{18}$ a la lucha e identidad del maestro:

Ante esta situación es urgente e importante recuperar el acumulado histórico del Movimiento Pedagógico Colombiano, que en sus luchas transformó la visión y conceptualización del docente, y enfrentó la posición que veía al docente como técnico o un operario, y planteó la

17 Aunque asistimos a una época de desconfianza y críticas constantes al sindicalismo en general, la sindicalización docente no ha desaparecido, aunque sí se ha disminuido el número de maestros que se vinculan por ejemplo a la Fecode, y realizan la lucha por sus derechos desde otros sindicatos, espacios presenciales y virtuales.

18 Mockus (1984) señalaba la impronta de su acción: "El Movimiento Pedagógico surge de la convergencia de dos problemáticas: El rechazo instruccional como estrategia de mejoramiento cualitativo, por cuanto entraña una descalificación del oficio del educador y una limitación de su autonomía intelectual y profesional y la voluntad de rescatar o más bien, de hacer por primera vez verdadera para el educador colombiano la identidad de trabajador de la cultura" (p. 32). 
importancia de reconocer al maestro y reconfigurar su identidad e imagen como intelectual de la pedagogía, un trabajador de la cultura y un ciudadano político. [...] La lucha por un nuevo estatuto tiene el reto de recuperar la condición para que el docente se asuma como un intelectual crítico (CEIDFecode, 2012, p. 27).

La explicación de ruptura y división de la profesión docente entre nuevos y antiguos maestros amparados por dos reglamentaciones vigentes advierte una relación de causa y efecto que pone en evidencia a la ley como constituyente de subjetividades que han desvertebrado el colectivo magisterial y menguando la lucha. ¿Será acaso que la ley es la causante de este decaimiento en la lucha? ¿Tiene ese poder que mina la resistencia? ¿Existen acaso otras fuerzas que han sido pasadas por alto en esta situación? Ahora bien, frente a los discursos de recuperación del Movimiento Pedagógico y sus aportes ¿Constituyen estos una directa interpelación a repensar la imagen del maestro hoy? O acaso ¿son denuncia de su docilidad?

El magisterio sindicalizado parece haberse quedado atrapado en esta queja, e imposibilitado para cumplir las demandas de un magisterio hoy conformado por licenciados, profesionales habilitados y normalistas que reclaman se asuman las consecuencias del decreto 1278 de 2002 para la profesión y se trabaje conjuntamente por mejorar sus condiciones y elevar el estatuto de su profesión. Mientras, otros insisten en recuperar para la profesión las condiciones de régimen especial y la definición de la profesión con base en la formación pedagógica del decreto 2277 de 1979. Podría afirmarse que son tantas las inconformidades de los maestros de un régimen y del otro que los propios maestros pasan por alto, que más allá de los efectos normativos y sus luchas reivindicativas, lo que está en juego es la condición misma del maestro ligada al estatuto de profesión de la docencia en el ámbito epistemológico, social y político.

Volverse a "preguntar por el maestro", en un escenario tan complejo que revela el deterioro de su condición, implica reflexionar sobre una serie de problematizaciones: ¿Qué significa ser maestro hoy? ¿Quién es el maestro? ¿Qué características distintivas tiene la docencia frente a otras profesiones? ¿Cuál es su estatuto social? ¿Qué papel cumple el maestro en la definición de las políticas y reformas educativas? ¿Qué nos dice su resistencia? ¿Qué entiende el maestro por calidad? ¿Qué entiende el maestro por excelencia? Se trata de pensar la condición del maestro desde la convergencia/tensión de distintas fuerzas, políticas, sociales, culturales, económicas.

Más aún, cuando coexisten en Colombia tendencias discursivas no muy delimitadas, no muy precisas 
que hacen circular discursos que perciben aún al maestro como un apóstol, como un pedagogo forjador de cultura, como una forma entre docentes, como una pieza clave de engranaje de políticas educativas. De su condición de oficio a su condición de profesión han de advertirse un sinnúmero de transformaciones que de la mano de las demandas de política nacional e internacional, de la aceptación y/o resistencia de los maestros, de la sanción social de las demandas educativas, han fraguado un destino lleno de exigencias, de incertidumbres y de críticas incesantes. Pareciera que hoy se percibe más al docente como un funcionario del Estado, que debe cumplir con la función que le ha sido encomendada, que como un profesional de la educación que sabe cómo dirigirla.

Varios estudios arrojan pistas importantes para pensar qué ha pasado con el maestro. Por ejemplo, los que se han ocupado de la práctica pedagógica y la identidad del maestro: Zuluaga (1988), que plantea una distinción entre los sujetos de la enseñanza, maestro y docente, para precisar la relación del primero con el método y del segundo con el saber que transmite y la norma; Martínez Boom (2010) cuyo trabajo refiere la dilución del maestro y su despersonificación en la función docente, entre otros. También los que se han ocupado de la relación docencia-reforma y sus efectos: el docente y la internalización de su rol de funcionario del Estado, la cosificación de la profesión de enseñar, la frustración docente (Díaz, 2010), la desautorización de los docentes (Vezub, 2005). Los que han trabajado la relación docencia-sociedad: las exigencias y la sobrecarga de responsabilidades a los docentes (Esteve, 2006), el desprestigio de la docencia (Vaillant, 2005), entre muchos otros que refieren distintos fenómenos a raíz de su malestar, su lugar en la encrucijada (Tiramonti, 2005), su insatisfacción (Braslavsky, 1994), sus

sentimientos de culpabilidad (Hargreaves, 2005). En definitiva, hay que apostarle a una mirada de estos fenómenos desde la perspectiva latinoamericana sobre la condición docente.

\section{La excelencia docente}

La idea del docente como clave del éxito para mejorar la calidad de la educación viene haciendo carrera desde hace algunos años en el discurso oficial del MEN, que, entre otros estudios, ha tenido como referente el informe de McKinsey (2007) que atribuye al "maestro" mejor preparado "la capacidad de conseguir 
resultados adecuados y de obtener más o mejores logros con medios limitados". Es decir, una fuente conveniente a los intereses de racionalización y productividad. En este sentido, se analiza la "efectividad docente" en relación directa con la tarea de enseñar y los resultados que alcanzan los estudiantes (MEN, 2009. Al tablero, No. 50). Lo que viene a representar una valoración de la excelencia docente delimitada por la efectividad como criterio para sopesar su rendimiento.

Bajo este esquema de medición de la calidad con base en los resultados, el slogan de la excelencia docente se convierte en el eje de una nueva reforma que tiene la esperanza de superar el fracaso de su antecesora, centrada en la idoneidad de los educadores, que no ha dado los resultados esperados: "Colombia se volvió a rajar en las pruebas internacionales de educación del Programa de Evaluación Internacional de Estudiantes (PISA)" (EI Tiempo, 9 de julio de 2014). Esto siembra algunas dudas: ¿No será acaso que no se está captando el problema en su compleja dimensión? ¿Puede concebirse la calidad de la educación colombiana solo desde la efectividad docente? ¿No será que la profesión de "maestro", devino en crisis por esta lógica en la que se le ha insertado? ¿No habrá que hilar más fino?

El papel de la opinión pública hoy se instala en el lugar común, sin cuestionar los enunciados que repite, sin atender cómo la forma maestro ha sido intervenida por distintas fuerzas (políticas, económicas, sociales, gremiales) que han minado el contenido y las luchas constituyentes de los maestros. Venderle a la sociedad la idea de que el maestro es el responsable de una política de calidad -que quizás no comparte- al tiempo que se le considera mal preparado, carente de liderazgo y deficitario para acometer los desafíos actuales, es una senda más en el laberinto de la crisis que le ha sido declarada. Mientras el peso de la excelencia se valida en nuevas rejillas de observación, medición, regulación y acompañamiento que no le dejan ni oscuridad ni respiro.

\section{Referencias bibliográficas}

Ávila, J. (2012). Despedagogización y desprofesionalización de la profesión docente en Colombia: el decreto 1278 de 2002. Educación y Cultura 95, pp. 26-31.

Bill \& Melinda Gates Foundation (2013). Ensuring fair and reliable measures of effective teaching. Recuperado el 8 de febrero de 2013 de http://www.metproject. org/

Braslavsky et al. (1994). Las características de la profesión maestro y la calidad de la educación en América Latina. En Unesco, Boletín 34. Proyecto Principal de Educación en América Latina y el Caribe. Orealc: Chile. Disponible en: http://unesdoc.unesco. org/images/0010/001002/1002 00s.pdf 
CEID-Fecode (2012). De negociaciones, imposiciones gubernamentales y un nuevo estatuto único de la profesión docente. Educación y Cultura, 95, pp. 11-15.

Cruel realidad económica de un egresado en Colombia. (2012, 5 de febrero). Portafolio.co Recuperado de http:// www.portafolio.co/economia/cruel-realidad-economica -un-egresado-colombia

Colombia, en el último lugar en nuevos resultados de pruebas PISA. (2014, 9 de julio). El Tiempo. Recuperado de http://www.eltiempo.com/estilo-de-vida/educacion/ colombia-en-el-ultimo-lugar-en-pruebas-pisa/14224736

Colombia es uno de los países con mayores cifras de matoneo. (2012, 15 de marzo). vanguardia.com. Recuperado de ttp:// www.vanguardia.com/actualidad/colombia/148157-colombia-es-uno-de-los-paises-con-mayores-cifras-de-matoneo

Díaz, B. A. (1983). Tarea docente. Una perspectiva grupal y psicosocial. Universidad Nacional Autónoma de México. México: Editorial Nueva Imagen. Disponible en: http:// www.revistadocencia.cl/pdf/20100729233046.pdf

Es un campanazo de alerta dice la Ministra de Educación (2013, 8 de diciembre). El Tiempo. Recuperado de: http://www.eltiempo.com/archivo/documento/CMS-13266300

Esteve, J. M. (1987): El malestar docente, Barcelona, Laia.

Fundación Compartir (2014). Tras la excelencia docente. Cómo mejorar la calidad de la educación para todos los colombianos. Puntoaparte Bookvertising. Bogotá.

Friedman, I. (1995). Student behavior patterns contributing to teacher burnout. Journal of Educational Research, 88 (5), 281-289.

Gómez-Buendía, H. y Losada-Lora, R. (1984). Organización y conflicto: la educación primaria oficial en Colombia. CIID, Bogotá.

Gaona, V. y Ocampo J. (2012). El estatuto docente del decreto ley 2277 de 1979 y las perspectivas de un nuevo estatuto. Educación y Cultura 95, pp. 14-18.

González, G. B. (2010) ¿Qué papel tiene el maestro en el mundo de la educación? Entrevista a Denisse Vaillant (noviembre 18 de 2010). González, B. Editor Colombia Incluyente. Recuperado de: http://www.colombiaincluyente.org/verop.php?id=14

Hargreaves, L.; Cunningham, M. et al. (2006). The status of teachers and the teaching profession: Views from inside and outside the profession. Interim Findings from the Teacher 
Status Project. Research Report. University of Cambridge.

IE (2013). En Colombia la docencia es de alto riesgo. Recuperado de http://www.ei-ie-al.org/index. php?option=com_content\&vie $\mathrm{w}=$ article \&id=65:en-colombiala-docencia-es-de-alto-riesgo\&c atid=65: colombia\&ltemid $=27$

Investigación ratifica hacinamiento en colegios del municipio (2013, 19 de mayo). Periodismopublico.com. Recuperado de http://periodismopublico. com/Investigacion-ratifica

Keiper, R. y Busselle, K. (1996). The rural educator and stress. RuralEducator, 17 (2), pp. 18-21.

La Quinta Pata (2013) Docencia: profesión peligrosa. Recuperado de http://la5tapatanet.blogspot. com/2013/06/docencia-profesion-peligrosa.html

Maestros del mundo critican pruebas PISA (2014, 13 de mayo). El Espectador. Recuperado de http://www.elespectador.com/ noticias/educacion/maestrosdelmundo-critican-pruebas-pisa-articulo-491995

Martínez Boom, A. (2010). La dilución del maestro. En Palabra Maestra 25. Fundación Compartir. Octubre. Bogotá-Colombia. Recuperado de http://www. palabramaestra.org/admin/ docs/1291299843Palabra\%20 Maestra\%2025\%20Final\%20 $\sin \% 20$ editorial.pdf

Martínez, Boom, A. (2014). ¿Maestros responsables de la inequidad? Semana.com. (9 de junio de 2014). Recuperado de http://www.semana.com/ educacion/articulo/albertomartinez-boom-miembro-de-laacademia-colombiana-de-pedagogia-analiza-el-estudio-dela-fundacion/391068-3

Martínez, M. (2012). De negociaciones, imposiciones gubernamentales y un nuevo estatuto único de la profesión docente. Educación y Cultura, 95, pp. 8-13.

Mckinsey y Company (2007). How the world's best performing school systems come out on top. Recuperado de: www.mckinsey. com/clientservice/socialsector/ ourpractices/philanthropy.asp

Marlow, L. et al. (1996). Teacher Job Satisfaction. Educational Resources Information Center, ED393802.

MEN (2009). Maestros competentes. Al tablero. No. 50 (mayo-junio de 2009). Recuperado de http://www.mineducacion.gov. co/1621/article-195576.html

MEN (2012). CVNE. Comunicado de prensa (8 de octubre de 2012). Recuperado de http://www.mineducacion.gov.co/cvn/1665/ w3-article-309936.html

MEN. (2014). Foro Maestro Siempre. Memorias. Bogotá.

Mockus, A. (1984). Movimiento Pedagógico y la defensa de la calidad de la educación pública. Educación y Cultura, 2, 6-10.

Natale, J. (1993). Why teachers leave. Executive Educator, 15 (7), 14-18. 
Preal (2010). El reconocimiento de los buenos docentes: una estrategia para elevar el estatus de la profesión. Sinopsis Educativa 29.

Reyes, Y. (2012) Maestros a mucho honor. (2012, 19 de febrero). El Tiempo Recuperado de http://m.eltiempo.com/opinion/columnistas/yolandareyes/ maestros-a-mucho-honor/11173124.

RCN (2012) 15 colegios de convenio en Bogotá están en condiciones insalubres. Disponible en: http://www.canalrcnmsn.com/ noticias/15_colegios_de_convenio_en_bogot\%C3\%A1_ est $\%$ C3\%A1n_en_condiciones_insalubres Consultado el 15 de mayo de 2014.

Ser maestro oficial, una profesión que está en crisis. (2012, 25 de abril). El Tiempo. Recuperado de http://www. eltiempo.com/vida-de-hoy/educacion/ARTICULO-WEB-NEW_ NOTA_INTERIOR-11656721.html

Se necesitan estímulos para que sea más atractivo ser profesor. (2012, 25 de abril). El Tiempo. Recuperado de http://www. eltiempo.com/vida-de-hoy/educacion/se-necesitan-estimulos-para-que-sea-mas-atractivo-ser-profesor_11656722-4

Tiramonti, G. (2005). La escuela en la encrucijada del cambio social. Educ. Soc., Campinas, 26 (92), 889-910.

Varkeys Gems Foundation (2013). The Global Teacher Status Index. Publicado por Varkeys Gems Foundation. Recuperado de https://www.varkeygemsfoundation.org/sites/default/files/ documents/2013GlobalTeacherStatusIndex.pdf

Vaillant, D. (2005). Formación de Docentes en América Latina. Re-inventando el modelo tradicional. Barcelona: Octaedro.

Vezub, L. (2005). El discurso de la capacitación docente. Una aproximación a las políticas de perfeccionamiento en la Provincia de Buenos Aires. Espacios en Blanco, Revista de Educación, 15, 211-242.

Young, T. (2004). An investigation of occupational stress among psychoeducational teachers in middle and southeastern Georgia. Humanities and Social Sciences, 64 (12 a), 44-45.

Zubiría, J. (2014). No basta tener buenos docentes. (junio 15). Semana.com. http://www.semana.com/educacion/articulo/ para-la-excelencia-educativa-no-solo-se-necesitan-mejoresmaestros/382193-3

Zuluaga, O. (1998). Pedagogía e historia. La Historicidad de la pedagogía. La enseñanza, un objeto de saber. Editorial Universidad de Antioquia. Anthropos, Siglo del Hombre Editores. 